\title{
Prediction of the lifetime productive and reproductive performance of Holstein cows managed for different lactation durations, using a model of lifetime nutrient partitioning
}

\author{
C. Gaillard, ${ }^{* 1}$ O. Martin, $†$ P. Blavy, $\dagger$ N. C. Friggens, $\dagger$ J. Sehested, ${ }^{*}$ and H. N. Phuong \\ *Department of Animal Sciences, Aarhus University, PO Box 50, 8830 Tjele, Denmark \\ †UMR Modélisation Systémique Appliquée aux Ruminants, INRA, AgroParisTech, Université Paris-Saclay, 75005 Paris, France \\ ‡Department of Economic Development, Jobs, Transport and Resources, Bundoora, 3083 Victoria, Australia
}

\begin{abstract}
The GARUNS model is a lifetime performance model taking into account the changing physiological priorities of an animal during its life and through repeated reproduction cycles. This dynamic and stochastic model has been previously used to predict the productive and reproductive performance of various genotypes of cows across feeding systems. In the present paper, we used this model to predict the lifetime productive and reproductive performance of Holstein cows for different lactation durations, with the aim of determining the lifetime scenario that optimizes cows' performance defined by lifetime efficiency (ratio of total milk energy yield to total energy intake) and pregnancy rate. To evaluate the model, data from a 16-mo extended lactation experiment on Holstein cows were used. Generally, the model could consistently fit body weight, milk yield, and milk components of these cows, whereas the reproductive performance was overestimated. Cows managed for repeated 12-, 14-, or 16-mo lactation all their life were simulated and had the highest lifetime efficiency compared with shorter (repeated 10-mo lactations: scenario N-N) or longer lactations (repeated 18-, 20-, or 22-mo lactations). The pregnancy rates increased slightly from a 10-mo to a 16-mo lactation but not significantly. Cows managed for a 16-mo lactation during their first lactation, followed by 10-mo lactations for the rest of their lives (EL-N scenario), had a similar lifetime efficiency as cows managed for 16-mo lactation all of their lives (EL-EL scenario). Cows managed for a 10-mo lactation during their first lactation, followed by 16 -mo lactations for the rest of their lives (N-EL scenario), had a similar lifetime efficiency as that of the $\mathrm{N}-\mathrm{N}$ scenario. The pregnancy rates of these 4 scenarios (N-N, EL-EL, N-EL, and EL-N) were similar to one another. To conclude, the GARUNS model was able
\end{abstract}

Received February 19, 2016.

Accepted July 14, 2016.

${ }^{1}$ Corresponding author: charlotte.gaillard@agrsci.dk to fit and simulate the extended lactation of Holstein cows. The simulated outputs indicate that managing the primiparous cows with a 16-mo extended lactation, followed by 10-mo lactations, allows their lifetime efficiency to increase and become similar to cows managed for 16-mo lactation during their entire lives. Further work should include health incidence (i.e., diseases) in the prediction model to have more accurate and realistic predictions of lifetime efficiency.

Key words: lifetime efficiency, nutrient partitioning, extended lactation, modelling

\section{INTRODUCTION}

High-yielding cows have been selected over generations for an increased milk yield (MY), which is unfortunately associated with impaired health and reproductive performance (Butler, 2000; Gilmore et al., 2011). The decrease in pregnancy rate is mainly due to the negative energy balance associated with high yields in early lactation (Lucy, 2001; Walsh et al., 2011) and the relationship between body lipid reserves and the reproductive cycle (Friggens, 2003). Consequently, the traditional 365-d calving interval (10-mo lactation) has become more challenging to achieve as pregnancy rates continue to decline. Moreover, the full capacity of the animals is not well exploited as the dry-off often occurs at a time when they are still producing a large amount of milk (Knight, 2005). An extended lactation management, such as delaying rebreeding until 8 mo after calving, would prolong the cow's lactation duration (Osterman and Bertilsson, 2003), decrease the number of calvings per year, decrease the number of health-risk periods associated with calving (Knight, 2005; Ingvartsen, 2006), and decrease farm methane emissions through having less replacement stock, which are known to be responsible for $27 \%$ of farm methane emissions (Garnsworthy, 2004). Within an extended lactation management, the cow is inseminated at a stage of lactation with a more positive energy balance and is dried off with a lower MY rather than the 
traditional 10-mo lactation system. However, to our best knowledge, no studies have been conducted to explore the long-term effect of extended lactation on cows' productive and reproductive performance. It is partly because experiments on extended lactation are time consuming, and the number of animals is often restricted. In this context, prediction models can be useful to forecast the consequences of different management strategies in terms of production and reproduction. The simulation of nutrient partitioning across physiological functions and according to genotypes has been the subject of several models (Dumas et al., 2008; Friggens et al., 2013) with the aim to predict the performance of an animal and help farmers make the best management decisions. A dynamic and stochastic model, referred to here as GARUNS, which takes into account the changing priorities of an animal during its life, and through repeated reproduction cycles, has been previously developed (Martin and Sauvant, 2010) and tested for cows managed for a 10-mo lactation, for different breeds and parities (Phuong et al., 2015).

Accordingly, the objectives of the present study were (1) to determine if the GARUNS model of Martin and Sauvant (2010) was able to fit individual curves of MY, BW, BCS, DMI, milk fat (MCF), milk protein (MCP), and milk lactose (MCL) of cows managed for 16 mo of lactation; (2) to determine if the full model, including the reproductive submodel of Phuong et al. (2016) can predict the reproductive performance of cows managed for a 16-mo lactation; and (3) to predict which lifetime scenarios, based on the lactation length, will be most beneficial in terms of performance and reproduction. It was hypothesized that lifetime efficiency and pregnancy rates would be maximized when first calving cows were allowed more time to reestablish pregnancy (16-mo lactation) compared with those with shorter intercalving intervals. This follows indications that extended lactations are more advantageous for primiparous cows than multiparous cows (Arbel et al., 2001; Osterman and Bertilsson, 2003) and that postponing rebreeding increases pregnancy rates (Schindler et al., 1991; Larsson and Berglund, 2000; Kolver et al., 2007).

\section{MATERIALS AND METHODS}

\section{Facilities and Animal}

The data were obtained from the REPROLAC experiment described by Gaillard et al. (2016b). This experiment was conducted at the Danish Cattle Research Centre at Aarhus University, AU-Foulum, Denmark, from November 2012 to January 2015, and approved by the Animal Experiments Inspectorate under the Danish Veterinary and Food Administration. A total of 62 Holstein cows from a nonseasonal dairy system, including 17 first parity cows, were managed for a 16mo lactation by delaying rebreeding to 220 DIM. All the cows were housed in a single pen with slatted floor and cubicles with mattresses. They had free access to water and were fed ad libitum through automatic feeders (Insentec RIC system, Marknesse, the Netherlands). Cows had access to an automatic milking unit (DeLaval AB, Tumba, Sweden) where they received $3 \mathrm{~kg}$ of extra concentrate per day and had to visit it at least twice a day. In the REPROLAC experiment, half of the cows were fed a diet enriched in energy in early lactation (on average the first $7 \mathrm{wk}$ of lactation) compared with the standard diet. To simplify the present analysis, and because the difference in energy between the diets was observed to have very few effects on the production variables (Gaillard et al., 2016a), only the standard diet was considered. This diet had an average energy density of $11.5 \mathrm{MJ}$ of $\mathrm{ME} / \mathrm{kg}$ of DM.

\section{Data Recording}

The MY was recorded at each individual milking in the milking robot, and the milk components (fat, protein, lactose, and cells) were measured every week. Daily BW was recorded through a platform scale (Danvaegt, Hinnerup, Denmark) in the milking robot. The BCS of all cows was scored manually every second week by the same 2 evaluators. A scale of 1 to 5 with 0.25-point increments was used (Ferguson et al., 1994). Daily DMI was calculated by adding the concentrate eaten at the milking robot and the DMI was registered by the automatic feeders.

\section{GARUNS Model}

The GARUNS model is a dynamic and stochastic model that takes into account the changing physiological priorities of an animal during its life and through repeated reproduction cycles (Martin and Sauvant, 2010). In this model, an individual cow is the unit modeled. The model is composed of a regulating submodel and an operating submodel. The regulating submodel describes the priorities in terms of Growth, Aging, body


born calf, and to the calf through Sucking (GARUNS), whereas the operating submodel distributes the energy between the physiological functions according to the priorities and the genetic scaling parameters. To simulate the differences between animals in genetic potential for milk production level, milk components, BW, and body reserves, the model uses the following genetic scaling parameters: peak MY potential $\left(\boldsymbol{\mu}_{\mathbf{Y}}\right)$, milk fat secretion $\left(\boldsymbol{\mu}_{\mathrm{F}}\right)$, milk protein secretion $\left(\boldsymbol{\mu}_{\mathrm{P}}\right)$, milk lactose secre- 
Table 1. Waiting period duration and culling rules used in the GARUNS model for the lactation durations simulated

\begin{tabular}{lcc}
\hline $\begin{array}{l}\text { Lactation } \\
\text { duration, }\end{array}{ }^{1}$ mo & $\begin{array}{c}\text { Voluntary waiting } \\
\text { period, }{ }^{2} \mathrm{~d}\end{array}$ & $\begin{array}{c}\text { Culling } \\
\text { rule, }\end{array}$ \\
\hline 10 & 60 & 160 \\
12 & 120 & 220 \\
14 & 180 & 280 \\
16 & 240 & 340 \\
18 & 300 & 400 \\
20 & 360 & 460 \\
22 & 420 & 520 \\
\hline
\end{tabular}

${ }^{1}$ Lactation duration is from calving to drying off.

${ }^{2}$ Waiting period $=$ days from calving to first insemination.

${ }^{3}$ Culling: maximum number of days allowed for a cow to get pregnant, otherwise the cow gets culled. Calculation: 5 cycles of $21 \mathrm{~d}+$ days from calving to first insemination.

tion $\left(\boldsymbol{\mu}_{\mathbf{L}}\right)$, nonlabile body mass at maturity $\left(\mathbf{w}_{\mathbf{M}}\right)$, and labile body mass mobilization index $\left(\boldsymbol{\mu}_{\mathrm{X}}\right)$. Moreover, to adapt the original model to the situation of extended lactation, the following parameters that regulate the lactation length and priority for milk production were also used: priority between the suckling calf and body reserves from calving to peak MY $\left(\mathbf{y}_{\mathbf{N}}\right)$ and after the peak MY $\left(\boldsymbol{\lambda}_{0}\right)$, and priority between the suckling calf and a newborn calf ( $\gamma$ and Uwea). The unit of $\mathrm{w}_{\mathrm{M}}$ is the kilogram, whereas the remaining parameters are dimensionless energy ratios $(\mathrm{MJ} / \mathrm{MJ})$. Moreover, the inputs of GARUNS are the energy density of the ration (eD), the genetic scaling parameters to describe an innate variability between animals in performance, and the reproductive timing parameters (i.e., age from birth to first pregnancy and intervals between calving and pregnancy). A reproduction submodel was then added by Phuong et al. (2016) to the GARUNS model using the predicted values of MY, BCS, and energy balance from the GARUNS model as inputs to stimulate reproductive responses in terms of pregnancy rate at first insemination and thereby productive lifetime (Figure 1).
The culling decisions for this new reproductive model are described in Phuong et al. (2016). In short, a cow is culled if it is not pregnant after 4 inseminations and if MY is below $25 \mathrm{~kg} / \mathrm{d}$. If MY is above $25 \mathrm{~kg} / \mathrm{d}$ after 4 inseminations and the cow is still not pregnant, a last insemination is allowed. Moreover, a cow managed for a 10-mo lactation is culled if it is not pregnant after 160 d postpartum, and after $340 \mathrm{~d}$ postpartum for a cow managed for a 16-mo lactation. The last culling rule for the different lactation lengths used in this paper is presented in Table 1. The effects of diseases on the animal's survivability are not currently incorporated in the model.

\section{Model Fitting to Individual Data}

To use GARUNS for simulating different extended lactation strategies, it was first necessary to evaluate its ability to fit the extended lactation data and to estimate the relevant genetic scaling parameters for extended lactation cows. These were then used to define the population of cows used in the simulation. Thus, using the observed data of the REPROLAC cows, the model was adjusted individually for each production measurement (MY, BW, DMI, BCS, MCF, MCP, and MCL), and the genetic-scaling parameters that allow the model to achieve best fit relative to the observed values were recorded. Modelmaker software version 3.0 (Cherwell Scientific Ltd., Oxford, UK) was used for the optimization based on a least squares procedure (Phuong et al., 2015). A total of 11 genetic scaling parameters (presented in Table 2) were adjusted.

\section{Model Fitting Evaluation}

Production Variables. The relative prediction error (RPE) was calculated to evaluate the ability of the GARUNS model to fit the observed data. As described

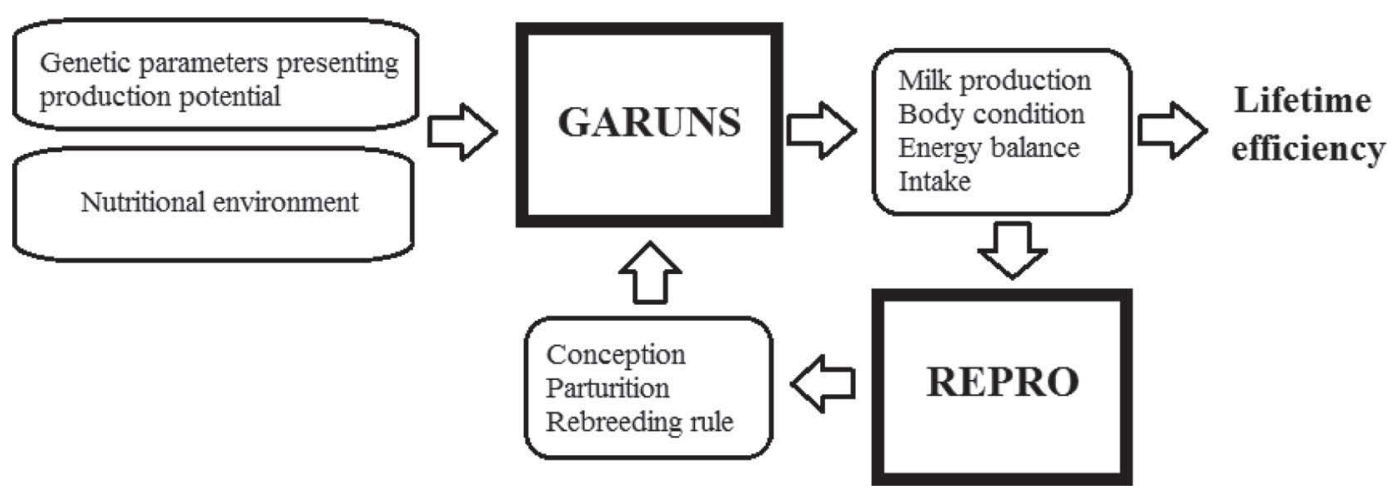

Figure 1. Schematic presentation of the model for predicting lifetime efficiency of individual cows that includes the GARUNS model (from Phuong et al., 2016). 
in Phuong et al. (2015), the root mean square error (RMSE) was first derived for each DIM across the N cows:

$$
\operatorname{RMSE}=\sqrt{\frac{1}{\mathrm{~N}} \sum_{\mathrm{i}=1}^{\mathrm{N}}\left(\mathrm{O}_{\mathrm{i}}-\mathrm{P}_{\mathrm{i}}\right)^{2}}
$$

where $\mathrm{O}_{\mathrm{i}}$ and $\mathrm{P}_{\mathrm{i}}$ are the ith observed and predicted values of MY, DMI, BW, BCS, MCF, MCP, or MCL, and $\mathrm{N}$ is the number of observations. Then the RPE was computed as $100 \times \mathrm{RMSE} /$ (mean of the observed data). Based on the work of Fuentes-Pila et al. (1996), it was assumed that a RPE $<10 \%$, between 10 and $20 \%$, and $>20 \%$ indicates a good, moderate, and poor prediction, respectively.

Reproduction Model. To evaluate the reproduction model, the observed values of days from calving to first service, days from calving to pregnancy, calving interval, and percentage of pregnant cows at first insemination were compared with the simulated values from the GARUNS model using a $t$-test.

\section{Scenarios and Statistical Analysis}

The simulation of different lifetime scenarios regarding the parity and the lactation length were implemented in $\mathrm{C}++$ programing language on the RECORD platform (Bergez et al., 2013). The lifetime of a cow is considered from birth to culling and is only influenced by reproductive performance and culling policy. For each scenario, a total of 300 cows were randomly generated with the genetic scaling parameters drawn using a normal law according to the mean and the standard deviation of the REPROLAC cows' parameters obtained from the model fitting process (Table 2).
First, several durations of lactation, presented in Table 1 , were tested to define which durations of lactation could be better than the 10-mo lactation in terms of milk production and reproductive parameters. A $t$-test was used to compare the pregnancy rate, the lifetime efficiency (total energy output in milk divided by the total energy intake, MJ/MJ), the MY per feeding day (total milk yield divided by total number of days of life, $\mathrm{kg} / \mathrm{d}$ ), the age at first calving, the lifespan (d), the total number of DIM during the life, the number of lactations in life, and the calving interval between the groups to find the optimum extended lactation duration regarding these criteria. Second, 4 lifetime scenarios were defined with a consideration of parity (primiparous or multiparous) and lactation duration. In the scenarios of N-N and EL-EL, the cows are managed for 10- and 16-mo lactations in their entire lives, respectively. In the N-EL scenario, the cows have a first lactation of 10 mo followed by 16-mo lactations. In the EL-N scenario, the cows have a first lactation of 16 mo followed by 10-mo lactations. The previous parameters were compared between these 4 scenarios to define which scenario optimizes the lifetime reproductive and productive performance.

\section{RESULTS}

\section{Step 1: GARUNS Fitting REPROLAC Data}

The GARUNS model was able to adequately fit the 16-mo extended lactation performance data as shown in Figure 2, where the observed values of MY, DMI, milk components, and BW of one cow are plotted (symbols) with the fitted curves of the model simulation (lines). Table 3 gives the means $( \pm \mathrm{SD})$ of the observed and simulated values for each variable, as well as the

Table 2. Description, mean, and SD of the genetic-scaling parameters ${ }^{1}$ of the REPROLAC 16-mo lactating Holstein cows derived by fitting to the GARUNS model, and of the 10-mo lactating Holstein cows of Phuong et al. (2015)

\begin{tabular}{|c|c|c|c|c|c|}
\hline \multirow[b]{2}{*}{ Parameter } & \multirow[b]{2}{*}{ Description } & \multicolumn{2}{|c|}{ REPROLAC } & \multicolumn{2}{|c|}{ Phuong et al. (2015) } \\
\hline & & Mean & $\mathrm{SD}$ & Mean & $\mathrm{SD}$ \\
\hline $\mathrm{w}_{\mathrm{M}}(\mathrm{kg})$ & Mature weight & 548 & 57 & 521 & 59 \\
\hline$\mu_{Y}$ & Milk production level & 1.4 & 0.2 & 1.25 & 0.25 \\
\hline$\lambda_{0}$ & Persistency & 0.001 & 0.0006 & 0.0017 & - \\
\hline $\mathrm{y}_{\mathrm{N}}$ & Start of the lactation & 0.68 & 0.27 & - & - \\
\hline Uwea & End of the lactation & 3.7 & 1.2 & - & - \\
\hline$\gamma$ & End of the lactation & 0.79 & 0.38 & 0.032 & - \\
\hline$\mu_{\mathrm{L}}$ & Milk lactose secretion & 0.99 & 0.01 & 1.0 & 0.04 \\
\hline$\mu_{\mathrm{F}}$ & Milk fat secretion & 1.1 & 0.11 & 1.2 & 0.1 \\
\hline$\mu_{\mathrm{P}}$ & Milk protein secretion & 1.04 & 0.07 & 1.0 & 0.1 \\
\hline$\mu_{\mathrm{X}}$ & Ability of mobilizing & 1.4 & 0.8 & 1.2 & 0.5 \\
\hline$\varphi$ & Weight of uterus/fetus & 0.58 & 0.02 & 0.58 & - \\
\hline
\end{tabular}

${ }^{1}$ The unit of the parameters is mentioned in the parentheses, otherwise unitless. 
associated relative prediction errors (RPE in \%). Body weight, MCP, and MCL were accurately predicted (RPE $\leq 10 \%$ ), whereas MY and MCF were acceptably predicted with RPE for all the cows to be 13.8 and $10.7 \%$, respectively, which in both cases indicate good fits of the model to the actual observations according to Fuentes-Pila et al. (1996) assumptions. However, BCS was poorly predicted $(\mathrm{RPE}>20 \%)$ and consequently resulted in a poor fit of DMI (RPE $>20 \%)$. In particular, the model underestimated BCS, whereas it overestimated DMI. No major changes of prediction accuracy were observed between parities (Table 3 ). Table 2 gives the description (mean and SD) of the parameters of GARUNS used to fit the REPROLAC data.

\section{Step 2: GARUNS Reproductive Model}

Table 4 presents the simulated reproductive performance of the REPROLAC Holstein cows. It shows that the model overpredicted the reproductive performance of these cows as the simulated cows had higher preg- nancy rate to first service $(+6 \%, P=0.02)$, number of days from calving to first service $(+23 \mathrm{~d}, P<0.01)$, number of days from calving to pregnancy $(+30 \mathrm{~d}, P$ $<0.01)$, and a longer calving interval $(+9 \mathrm{~d}, P<0.01)$ than the observed values.

\section{Step 3: Production and Reproduction Performance for Different Planned Lactation Durations}

Figure 3 shows that the pregnancy rate was significantly increased in an 18-mo lactation compared with a 10 -mo lactation $(P=0.05)$. Pregnancy rates were also higher for shorter lactations $(12,14$, and $16 \mathrm{mo})$ compared with a 10-mo lactation, although the difference was not statistically significant $(P=0.34, P=$ 0.47 , and $P=0.73$, respectively). Cows managed for $>18$-mo lactation had a similar pregnancy rate at first insemination as those of an 18-mo lactation. The number of inseminations per pregnancy was similar among the scenarios $(2.1 \pm 0.1$ inseminations, $P>0.5)$. The herd average lifetime efficiency and the production per
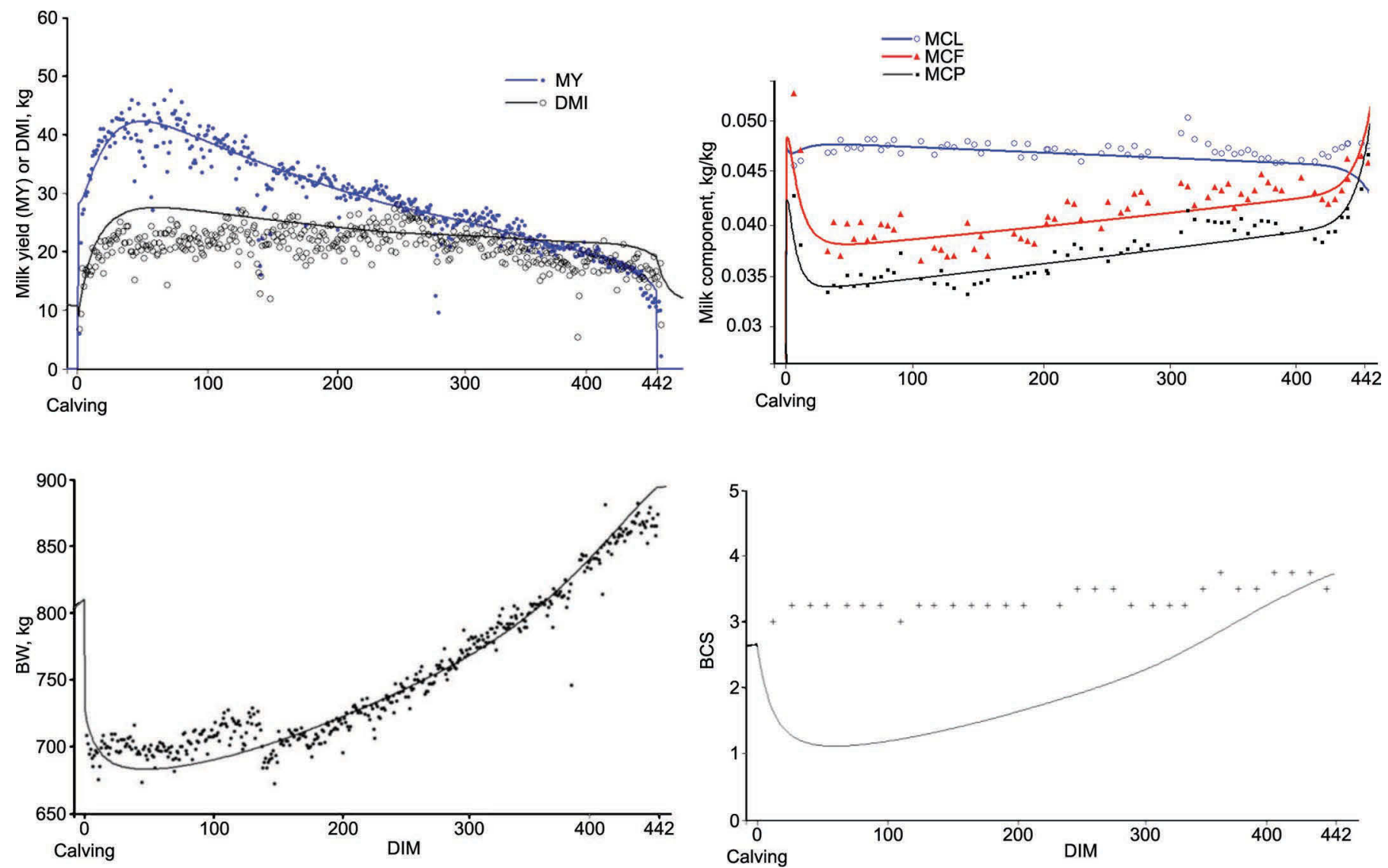

Figure 2. Observations (symbols) and associated fitted curves from the model simulation (solid lines) of milk yield (MY, kg/d), DMI (kg/d), BW $(\mathrm{kg})$, milk fat concentration $(\mathrm{MCF}, \mathrm{kg} / \mathrm{kg}$ ), milk protein concentration $(\mathrm{MCP}, \mathrm{kg} / \mathrm{kg}$ ), and milk lactose concentration $(\mathrm{MCL}, \mathrm{kg} / \mathrm{kg}$ ) of a selected cow. Color version available online. 
Table 3. GARUNS model accuracy for predicting milk yield (MY), DMI, BW, BCS, milk fat concentration (MCF), milk protein concentration (MCP), and milk lactose concentration (MCL) of Danish Holstein managed for a 16-mo lactation

\begin{tabular}{llccc}
\hline Variable & Parity & $\begin{array}{c}\text { Mean } \\
\text { observed } \pm \mathrm{SD}\end{array}$ & $\begin{array}{c}\text { Mean } \\
\text { simulated } \pm \mathrm{SD}\end{array}$ & $\begin{array}{c}\text { RPE, }{ }^{1} \\
\%\end{array}$ \\
\hline $\mathrm{MY}, \mathrm{kg} / \mathrm{d}$ & All cows & $32.30 \pm 7.27$ & $33.55 \pm 7.14$ & 13.84 \\
& Primiparous & $29.73 \pm 4.22$ & $31.16 \pm 3.78$ & 13.00 \\
$\mathrm{DMI}, \mathrm{kg} / \mathrm{d}$ & Multiparous & $33.49 \pm 8.67$ & $33.67 \pm 10.49$ & 13.77 \\
& All cows & $21.41 \pm 3.09$ & $23.97 \pm 3.17$ & 19.56 \\
& Primiparous & $18.26 \pm 2.89$ & $21.38 \pm 1.77$ & 22.65 \\
$\mathrm{BW}, \mathrm{kg}$ & Multiparous & $18.23 \pm 2.89$ & $20.98 \pm 2.54$ & 22.62 \\
& All cows & $684 \pm 54$ & $686 \pm 46$ & 3.00 \\
$\mathrm{BCS}, \mathrm{point}$ & Primiparous & $633 \pm 56$ & $635 \pm 46$ & 3.28 \\
& Multiparous & $708 \pm 53$ & $709 \pm 46$ & 2.87 \\
$\mathrm{MCF}, \mathrm{kg} / \mathrm{kg}$ & All cows & $3.31 \pm 0.22$ & $2.71 \pm 0.42$ & 27.37 \\
& Primiparous & $3.25 \pm 0.17$ & $3.03 \pm 0.34$ & 20.30 \\
$\mathrm{MCP}, \mathrm{kg} / \mathrm{kg}$ & Multiparous & $3.33 \pm 0.25$ & $2.57 \pm 0.46$ & 30.81 \\
& All cows & $0.042 \pm 0.004$ & $0.041 \pm 0.008$ & 10.67 \\
$\mathrm{MCL}, \mathrm{kg} / \mathrm{kg}$ & Primiparous & $0.04 \pm 0.005$ & $0.040 \pm 0.002$ & 10.81 \\
& Multiparous & $0.043 \pm 0.004$ & $0.042 \pm 0.01$ & 10.59 \\
& All cows & $0.035 \pm 0.003$ & $0.034 \pm 0.005$ & 10.19 \\
& Primiparous & $0.036 \pm 0.003$ & $0.032 \pm 0.002$ & 12.17 \\
& Multiparous & $0.035 \pm 0.004$ & $0.035 \pm 0.006$ & 9.26 \\
& All cows & $0.048 \pm 0.001$ & $0.049 \pm 0.002$ & 3.93 \\
& Primiparous & $0.049 \pm 0.001$ & $0.049 \pm 0.001$ & 2.92 \\
& Multiparous & $0.048 \pm 0.001$ & $0.049 \pm 0.002$ & 4.41 \\
\hline
\end{tabular}

${ }^{1} \mathrm{RPE}=$ relative prediction error.

feeding day increased as lactation length was extended from 10 to 12 mo $(P<0.001)$, were similar among $12-$, $14-$, and 16-mo lactations $(P>0.05)$, and started to decrease when the lactation length was $\geq 18$ mo. The efficiency and the milk production per feeding day for a 22-mo lactation were similar to those of a 10-mo lactation $(P=0.94)$. The herd average lifetime, the number of lactations per cow, and the total number of days in milk augmented with an increasing lactation length $(P$ $<0.01)$ and were similar for a 16- and 18-mo lactation $(P=0.08, P=0.28$, and $P=0.25$, respectively; Figure 4$)$. When comparing longer lactations (20 and 22 mo) with a 16-mo lactation, the number of lactations per lifetime decreased $(P<0.01)$, the life duration increased $(P<0.01)$, and the total number of days in milk stayed stable $(P=0.70)$. Regarding these 3 criteria (reproduction, production, and life duration), the 16-mo lactation was chosen as the optimum extended lactation duration for step 4 .

\section{Step 4: Best Life Scenario}

The 4 lifetime scenarios (N-N, EL-N, N-EL, and ELEL) had similar pregnancy rates (i.e., between $\mathrm{N}-\mathrm{N}$ and EL-EL, $P=0.73$; Figure 3 ) and number of inseminations per pregnancy $(2.1 \pm 0.1$ inseminations, $P>0.5)$. The calving interval increased with the extended duration of the lactations $(P>0.01$; Figure 5$)$. The EL-N scenario had the same calving interval as the 12-mo lactation scenario $(P=0.06)$ The EL-EL and EL-N scenarios had a higher efficiency than the scenarios of $\mathrm{N}-\mathrm{N}$ and N-EL $(P<0.01)$. The N-N scenario had the lowest MY per feeding day, whereas the highest value was observed for the EL-EL scenario. The MY per feeding day was lower for the scenario N-N than EL-N $(P<$ $0.001)$, for the scenario EL-N than N-EL $(P=0.025)$, and for the scenario N-EL than EL-EL $(P=0.015)$. The EL-EL scenario had higher life duration and number of lactations than those of other scenarios (Figure 4).

Table 4. Mean $( \pm \mathrm{SD})$ of observed and simulated reproductive data for the REPROLAC Holstein cows managed for 16 mo lactation

\begin{tabular}{lccc}
\hline Item & Observed & Simulated & $P$-value \\
\hline First service pregnancy, \% & $40 \pm 5$ & $46 \pm 5$ & 0.02 \\
Days from calving to first service, d & $227 \pm 13$ & $250 \pm 16$ & $<0.01$ \\
Days from calving to pregnancy, d & $251 \pm 37$ & $281 \pm 6$ & $<0.01$ \\
Calving interval, d & $541 \pm 20$ & $550 \pm 29$ & $<0.01$ \\
\hline
\end{tabular}

${ }^{1}$ The difference between the observed and simulated values is indicated by the $P$-value resulting from a $t$-test. 


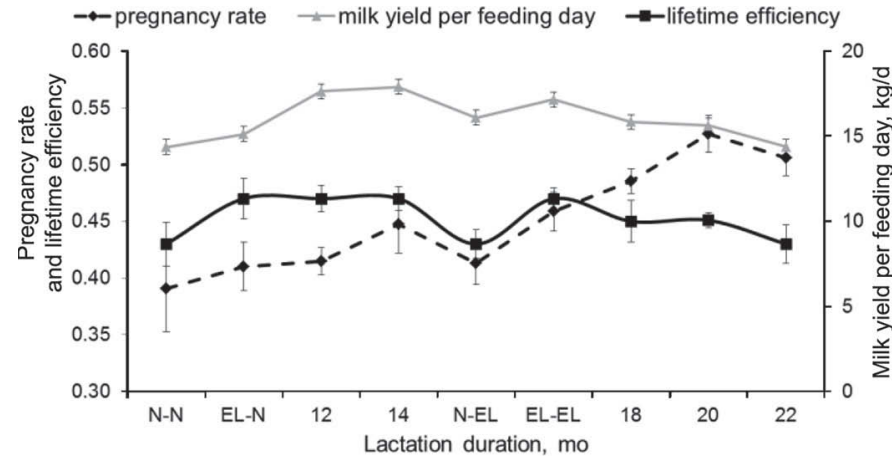

Figure 3. Prediction of pregnancy rate (\%), lifetime efficiency (total milk energy yield/total energy intake over the lifetime, MJ/MJ), and milk production per feeding day (total milk yield total/duration of life, $\mathrm{kg} / \mathrm{d}$ ) of Holstein cows obtained for lactations of different durations (mo) or scenario ( $\mathrm{N}-\mathrm{N}=10$-mo lactations for the whole lifetime, EL-N $=16$-mo first lactation followed by 10-mo lactations, N-EL = 10 -mo first lactation followed by 16 -mo lactations, EL-EL $=16$-mo lactations for the whole lifetime).

The number of lactations per life and the life durations were similar between the N-N and EL-N scenarios $(P$ $=0.61$ and $P=0.24$, respectively) and were lower than those of the N-EL and EL-EL scenarios. The number of lactations per life and the life durations were lower for the N-EL scenario compared with the EL-EL scenario $(P=0.04$ and $P=0.02$, respectively).

\section{DISCUSSION}

The GARUNS model was able to fit the 16-mo lactation data of Holstein cows. Lifetime scenarios with different lactation durations were successfully simulated. The lifetime efficiency, the pregnancy rates, and the

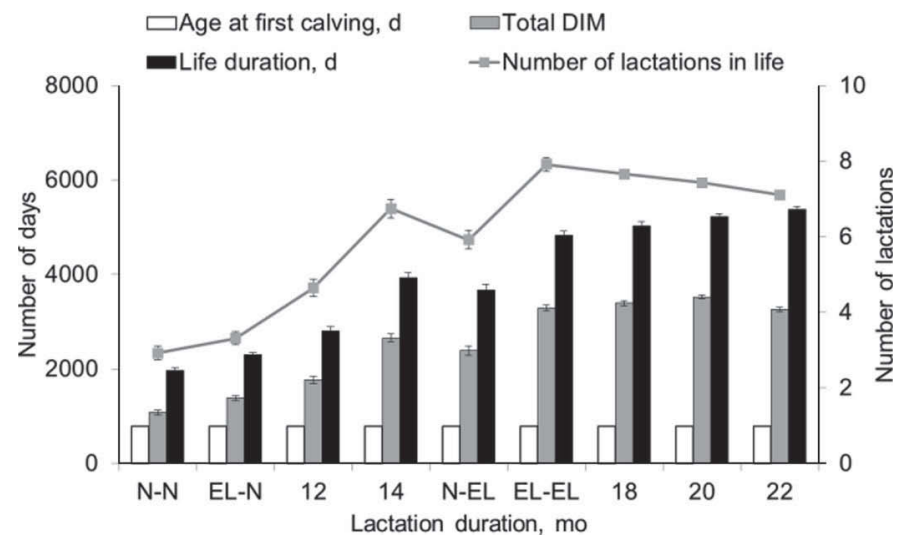

Figure 4. Prediction of life duration (d), number of lactations in life, and age at first calving (d) of Holstein cows for different lactation durations (mo) or scenario $(\mathrm{N}-\mathrm{N}=10$-mo lactations for the whole lifetime, EL-N = 16-mo first lactation followed by 10-mo lactations, $\mathrm{N}$-EL $=10$-mo first lactation followed by 16-mo lactations, EL-EL $=$ 16-mo lactations for the whole lifetime). lifetime duration were the main outputs varying between the proposed scenarios.

\section{Model Fitting}

Genetic Parameters. The genetic scaling parameters presented in Table 2 can be compared with those of the Danish Holstein cows in Phuong et al. (2015; also included in Table 2) managed for a 10-mo lactation. The milk production level $\left(\mu_{\mathrm{Y}}\right)$ of the REPROLAC cows, managed for a 16-mo lactation, was 12 percentage units higher than the one of Phuong et al. (2015). This is probably because these Holstein cows were coming from different herds fed with different energy density diets (11.5 MJ of ME versus 11.1 MJ of ME, respectively) and the results were recorded at different years and the genetic progress of the last decade might explain the increased milk potential (in Phuong et al., 2015), data sets were recorded from 2011 to 2014, whereas the present data were recorded from 2012 to 2015). The $\mu_{\mathrm{L}}$ and $\mu_{\mathrm{F}}$ parameters (lactose and fat concentrations in milk) were 1 and 9 percentage units, respectively, higher for Phuong et al. (2015) compared with the REPROLAC parameters, which was expected as these parameters are negatively correlated with the level of production. The persistency and level of production were independent parameters. The other parameters were not significantly different, indicating that the interval from calving to pregnancy can be considered as the main effect on the lactation shape. These results suggest that the same genetic scaling parameters can be used to build scenarios of different lactation durations.

Production and Reproduction Performance. The GARUNS model was able to fit the production

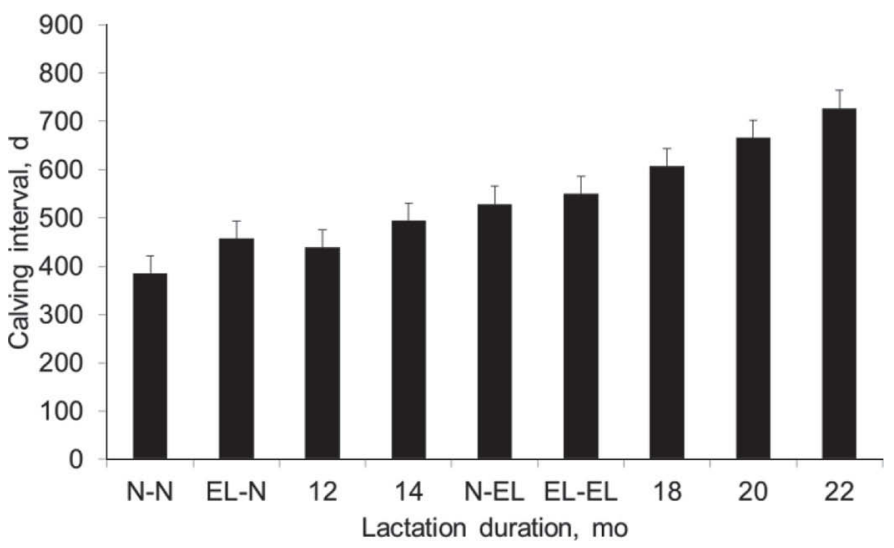

Figure 5. Calving intervals (d) for different lactation durations (mo) or scenarios $(\mathrm{N}-\mathrm{N}=10$-mo lactations for the whole lifetime, EL-N $=16$-mo first lactation followed by 10 -mo lactations, N-EL $=$ 10-mo first lactation followed by 16 -mo lactations, EL-EL $=16$-mo lactations for the whole lifetime). 
data of Holstein cows managed for extended lactation. Our results are in accordance with those reported by Phuong et al. (2015): the model accurately predicted individual BW and milk components and acceptably predicted MY. The model underestimated BCS and consequently overestimated DMI (because predicted DMI is an outcome of the predicted energy requirement, including body reserves). The observed DMI was actually lower than the predicted one, and consequently, the observed efficiency (MY/DMI) is expected to be slightly higher than the predicted efficiency. The model overestimated the reproductive performance of the REPROLAC cows $(+10 \%$ for all parameters, apart from calving interval where it is only $+2 \%$ ). The simulated outputs of pregnancy rate at first insemination (46 $\pm 5 \%$ ) are comparable with those reported in the literature of approximately $48 \%$ for Holstein cows (Kolver et al., 2007). Cows managed for a longer lactation than 10 mo are often observed to have an improved pregnancy rate at first service although the difference is not always statistically significant: 46 vs. $64.4 \%(P>$ 0.05; Schindler et al., 1991), 49 vs. 56\% (Larsson and Berglund, 2000), 19 vs. $48 \%(P>0.05$; Kolver et al., 2007), 35\% for both (van Amburgh et al., 1997), and 40.3 vs. $43.5 \%(P>0.05)$ (Arbel et al., 2001). In general, postponing rebreeding to a period of more positive energy balance affects the pregnancy rates positively. Thus, in this study, the simulated gain in pregnancy rate for 16 mo of lactation seemed plausible.

Model Limitations. The health risks often encountered in the life of a cow (i.e., mastitis, lameness, and ketosis) were not taken into account in this model. Such problems would negatively influence the production variables as well as the pregnancy rates and lifetime (Esposito et al., 2014). Consequently, in the current model, the production and reproduction values were predicted for animals that would never get sick, whereas they would be slightly different in reality. To take into account the health risks in GARUNS, a health submodel could be built and integrated into the actual model. This submodel should include the effect of general diseases on survivability as it has been shown that diseases negatively affect pregnancy rates, directly (metritis, retained placenta) by decreasing fertility (Esposito et al., 2014) or indirectly (mastitis, ketosis, acidosis, lameness) by decreasing DMI and consequently increasing negative energy balance, which affects negatively the ability of the animals to conceive (Butler, 2000; Reksen et al., 2002; Liefers et al., 2003; Patton et al., 2007). The MY at drying-off and the drying-off technique could also be incorporated into the health submodel as the stagnant milk contained in the mammary gland at drying-off is lower in natural protective factors such as immunoglobulins, so a high
MY at drying-off would increase the risk of infections (Bushe and Oliver, 1987; Paape et al., 1992). The use of an intermittent cessation of milking might help reduce infections compared with an abrupt cessation of milking (Newman et al., 2009).

\section{Model Predictions}

Realistic Outputs. The increase in pregnancy rate with the progressively extending lactation duration is in accordance with the literature (Schindler et al., 1991; Bertilsson et al., 1997; Kay et al., 2007). The absence of significant difference in predicted pregnancy rates, or number of inseminations per pregnancy, between 10and 16-mo lactations is in accordance with other results of the REPROLAC experiment comparing the reproductive outcomes between the 10-mo lactation and the 16-mo lactation (Gaillard et al., in press). From the 18-mo lactation, lifetime efficiency and MY per feeding day decreased compared with shorter lactations, which is in accordance with the previous studies. Milk yield is a driver of efficiency (MY/DMI), and thus, for long lactations (>10-mo), there are more days with lowerthan-average MY, which might explain the decrease in efficiency (Osterman and Bertilsson, 2003; Kolver et al., 2007). This also highlights the value of using a model like GARUNS to define the optimum duration of a lactation found to be 16 mo in terms of efficiency and pregnancy rates. This is in accordance with Auldist et al. (2007) and Kolver et al. (2007) who found that a 16-mo lactation was the more profitable way to extend lactation for a pasture-based system. This decrease in lifetime efficiency for a long lactation might also come from the fact that, as in real life, the GARUNS model has a built-in function (the A in GARUNS) to describe the descending priorities for vital functions such as survival and reproduction as animals age. It is assumed that the senescence process starts at first conception, and the value of $\mathrm{A}$ reaches the asymptote of 1 at 7,000 $\mathrm{d}$, which represents the state of being old leading to death. Consequently, it limits the longevity (productive life) to around $10 \mathrm{yr}$ although animals can live up to 20 yr as shown by Figure 2 in Martin and Sauvant (2010). It also places a natural limit on the benefits of very long lactations because cows cannot manage enough lactations to compensate for the reduced number of lactation peaks. Another possibility is that the benefits of late rebreeding decrease progressively as lactation duration increases.

For the 10-mo lactation scenario, the simulated value of lifetime $(1,969 \pm 1,095 \mathrm{~d})$ is in accordance with other studies where it varies from 1,762 to 2,200 d (Pritchard et al., 2013; CRV, 2014; Phuong et al., 2016). The average number of lactations $( \pm \mathrm{SD})$ for the 10 -mo lactation 
scenario was $2.92 \pm 3.03$, which is also in accordance with literature [3.3 lactations in Knaus (2009) and 3.0 lactations in Hare et al. (2006)]. The high values of lifetime predicted for the extended lactation scenarios (i.e., 8 lactations for a 16-mo scenario) might be because in the model the lifetime is mainly defined by the reproductive performance and the culling rules, as the effects of diseases are currently not incorporated in the model (Phuong et al., 2016). Old literature reported significant numbers of cows with 8 lactations (Lush and Shrode, 1950), but no actual experimental studies can be cited to evaluate these numbers, which indicates the lack of knowledge on extended lactation systems from a lifetime perspective.

Environment and Economy. From an environmental point of view, the extended lactation scenarios proposed in this paper should reduce methane emissions. The model of Garnsworthy (2004) shows that a herd with improved longevity has a lower environmental effect, as lowering the number of heifer replacements, which produces $27 \%$ of the methane on farms, mitigates methane emissions. As proposed by Phuong et al. (2016), the GARUNS model could also include a calculation of the economic effect of longer lactations. This would provide more information on the value of the efficiency of each scenario proposed in the present paper. The model of Jones (2005), for example, calculates the effects of reducing annual milk production to extend the productive life of dairy cows and concludes that the net financial effect of cutting milk production for a longer productive life of dairy cows was generally a loss.

Optimum Lifetime Scenario. The 2 best scenarios in terms of production and reproduction performance were EL-N and EL-EL. With respect to reproductive management of primiparous cows, a 16-mo lactation seems to be most beneficial for lifetime efficiency. This is in accordance with previous results where extended lactation seemed more advantageous for primiparous than multiparous cows (Arbel et al., 2001; Osterman and Bertilsson, 2003). This is linked to primiparous cows having a higher persistency than multiparous cows, so they can be inseminated later with less loss of milk (Ratnayake et al., 1998). In our case, this management shows that a first lactation of 16 mo will have an effect on the efficiency of the cow for the rest of its life. The primiparous cows benefit from an extended lactation as they have more time to finish growing while producing a lower amount of milk than the multiparous cows. They consequently start their second lactation at an older age and a bigger size, and it has been shown that BW at calving has a positive influence on milk production (Roche et al., 2007). It seems to be the key element here, as the benefit of extended lactation was only seen for EL-N and EL-EL scenarios and thus for primiparous cows with 16 mo of lactation. Bringing the extended lactation later in the cow's life, such as in the N-EL scenario, did not add any value in terms of productive and reproductive performance. Regarding the EL-EL scenario, even though the life duration was improved compared with the N-N and the EL-N scenarios, lifetime efficiency (as defined in this study) was not better than that in EL-N.

\section{CONCLUSIONS}

The GARUNS model was able to fit and simulate productive and reproductive of Holstein cows under an extended lactation situation. Further work should include health incidents to the prediction model to have more accurate predictions on the lifetime efficiency. Regarding our results and the need of improvements of the model, the "safer best" lifetime scenario seems to be EL-N (primiparous with 16-mo lactation only) where the efficiency was improved without changing the other parameters.

\section{ACKNOWLEDGMENTS}

The authors thank The Danish Council for Strategic Research, The Programme Commission on Health, Food and Welfare for the financial support of the REPROLAC experiment. We acknowledge the staff at the Danish Cattle Research Centre for their highly committed effort to run the experiment. We acknowledge technicians Connie H. Middelhede and Martin Bjerring (AU, Foulum, Denmark) for their effective efforts to generate data, as well as Beatriz Castro Dias Cuyabano (AU, Foulum) for her help with data handling.

\section{REFERENCES}

Arbel, R., Y. Bigun, E. Ezra, H. Sturman, and D. Hojman. 2001. The effect of extended calving intervals in high lactating cows on milk production and profitability. J. Dairy Sci. 84:600-608.

Auldist, M. J., G. O’Brien, D. Cole, K. L. Macmillan, and C. Grainger. 2007. Effects of varying lactation length on milk production capacity of cows in pasture-based dairying systems. J. Dairy Sci. 90:3234-3241.

Bergez, J. E., P. Chabrier, C. Gary, M. H. Jeuffroy, D. Makowski, G. Quesnel, E. Ramat, H. Raynal, N. Rousse, D. Wallach, P. Debaeke, P. Durand, M. Duru, J. Dury, P. Faverdin, C. GascuelOdoux, and F. Garcia. 2013. An open platform to build, evaluate and simulate integrated models of farming and agro-ecosystems. Environ. Model. Softw. 39:39-49.

Bertilsson, J., B. Berglund, G. Ratnayake, K. SvennerstenSjaunja, and H. Wiktorsson. 1997. Optimising lactation cycles for the highyielding dairy cow. A European perspective. Livest. Prod. Sci. 50:5-13.

Bushe, T., and S. P. Oliver. 1987. Natural protective factors in bovine mammary secretions following different methods of milk cessation. J. Dairy Sci. 70:696-704. 
Butler, W. R. 2000. Nutritional interactions with reproductive performance in dairy cattle. Anim. Reprod. Sci. 60-61:449-457.

CRV. 2014. Dutch cows excel in longevity. Accessed Dec. 4, 2014. https:// global.crv4all.com/aboutus/publications/highlights/79396/.

Dumas, A., J. Dijkstra, and J. France. 2008. Mathematical modelling in animal nutrition: A centenary review. J. Agric. Sci. 146:123-142.

Esposito, G., P. C. Irons, E. C. Webb, and A. Chapwanya. 2014. Interactions between negative energy balance, metabolic diseases, uterine health and immune response in transition dairy cows. Anim. Reprod. Sci. 144:60-71.

Ferguson, J. D., D. T. Galligan, and N. Thomsen. 1994. Principal descriptors of body condition score in Holstein cows. J. Dairy Sci. 77:2695-2703.

Friggens, N. C. 2003. Body lipid reserves and the reproductive cycle: Towards a better understanding. Livest. Prod. Sci. 83:219-236.

Friggens, N. C., L. Brun-Lafleur, P. Faverdin, D. Sauvant, and O. Martin. 2013. Advances in predicting nutrient partitioning in the dairy cow: Recognizing the central role of genotype and its expression through time. Animal 7:89-101.

Fuentes-Pila, J., M. A. DeLorenzo, D. K. Beede, C. R. Staples, and J. B. Holter. 1996. Evaluation of equations based on animal factors to predict intake of lactating Holstein cows. J. Dairy Sci. 79:1562-1571.

Gaillard, C., N. C. Friggens, M. Taghipoor, M. R. Weisbjerg, J. O. Lehmann, and J. Sehested. 2016b. Effects of an individual weightadjusted feeding strategy in early lactation on milk production of Holstein cows during extended lactation. J. Dairy Sci. 99:22212236 .

Gaillard, C., J. Sehested, and M. Vestergaard. Effects of delayed insemination on the reproductive performance of Holstein cows. J. Agric. Sci. Technol. A-B In press.

Gaillard, C., M. Vestergaard, M. R. Weisbjerg, and J. Sehested. 2016a. Effects of live weight adjusted feeding strategy on plasma indicators of energy balance in Holstein cows managed for extended lactation. Animal 10:633-642.

Garnsworthy, P. C. 2004. The environmental impact of fertility in dairy cows: A modelling approach to predict methane and ammonia emissions. Anim. Feed Sci. Technol. 112:211-223.

Gilmore, H. S., F. J. Young, D. C. Patterson, A. R. G. Wylie, R. A Law, D. J. Kilpatrick, C. T. Elliott, and C. S. Mayne. 2011. An evaluation of the effect of altering nutrition and nutritional strategies in early lactation on reproductive performance and estrous behavior of high-yielding Holstein-Friesian dairy cows. J. Dairy Sci. 94:3510-3526.

Hare, E., H. D. Norman, and J. R. Wright. 2006. Survival rates and productive herd life of dairy cattle in the United States. J. Dairy Sci. 89:3713-3720.

Ingvartsen, K. L. 2006. Feeding- and management-related diseases in the transition cow - Physiological adaptations around calving and strategies to reduce feeding-related diseases. Anim. Feed Sci. Technol. 126:175-213.

Jones, B. L. 2005. The economic trade-offs between annual milk production and the productive lives of dairy cows. Centre for Dairy Profitability, University of Wisconsin.

Kay, J. K., P. W. Aspin, C. V. C. Phyn, J. R. Roche, and E. S. Kolver. 2007. Production and physiological indicators to select cows suitable for extended lactations. Proc. N.Z. Soc. Anim. Prod. $67: 315-319$.

Knaus, W. 2009. Dairy cows trapped between performance demands and adaptability. J. Sci. Food Agric. 89:1107-1114.

Knight, C. H. 2005. Extended lactation: Turning theory into reality. Adv. Dairy Tech. 17:113-123.

Kolver, E. S., J. R. Roche, C. R. Burke, J. K. Kay, and P. W. Aspin. 2007. Extending lactation in pasture-based dairy cows: I. Genotype and diet effect on milk and reproduction. J. Dairy Sci. 90:5518-5530.
Larsson, B., and B. Berglund. 2000. Reproductive performance in cows with extended calving interval. Reprod. Domest. Anim. 35:277280

Liefers, S. C., R. F. Veerkamp, M. Pas, C. Delavaud, Y. Chilliard, and T. van der Lende. 2003. Leptin concentrations in relation to energy balance, milk yield, intake, live weight, and estrus in dairy cows. J. Dairy Sci. 86:799-807.

Lucy, M. C. 2001. ADSA Foundation Scholar Award-Reproductive loss in high-producing dairy cattle: Where will it end? J. Dairy Sci. 84:1277-1293.

Lush, J. L., and R. R. Shrode. 1950. Changes in milk production with age and milking frequency. J. Dairy Sci. 33:338-357.

Martin, O., and D. Sauvant. 2010. A teleonomic model describing performance (body, milk and intake) during growth and over repeated reproductive cycles throughout the lifetime of dairy cattle. 1. Trajectories of life function priorities and genetic scaling. Animal 4:2030-2047.

Newman, K. A., P. J. Rajala-Schultz, F. J. Degraves, and J. Lakritz. 2009. Association of milk yield and infection status at dry-off with intramammary infections at subsequent calving. J. Dairy Res. 77:99-106.

Osterman, S., and J. Bertilsson. 2003. Extended calving interval in combination with milking two or three times per day: Effects on milk production and milk composition. Livest. Prod. Sci. 82:139 149.

Paape, M. J., R. H. Miller, M. D. Young, and R. R. Peters. 1992. Influence of involution on intramammary phagocytic defense mechanisms. J. Dairy Sci. 75:1849-1856.

Patton, J., D. A. Kenny, S. McNamara, J. F. Mee, F. P. O'Mara, M. G. Diskin, and J. J. Murphy. 2007. Relationships among milk production, energy balance, plasma analytes, and reproduction in Holstein-Friesian cows. J. Dairy Sci. 90:649-658.

Phuong, H. N., P. Blavy, O. Martin, P. Schmidely, and N. C. Friggens. 2016. Modelling impacts of performance on the probability of reproducing, and thereby on productive lifetime, allow prediction of lifetime efficiency in dairy cows. Animal 10:106-116.

Phuong, H. N., O. Martin, I. J. M. de Boer, K. L. Ingvartsen, P. Schmidely, and N. C. Friggens. 2015. Deriving estimates of individual variability in genetic potentials of performance traits for 3 dairy breeds, using a model of lifetime nutrient partitioning. J. Dairy Sci. 98:618-632.

Pritchard, T., M. Coffey, R. Mrode, and E. Wall. 2013. Understanding the genetics of survival in dairy cows. J. Dairy Sci. 96:3296-3309.

Ratnayake, D., B. Berglund, J. Bertilsson, M. Forsberg, and H. Gustafsson. 1998. Fertility in dairy cows managed for calving intervals of 12, 15 or 18 months. Acta Vet. Scand. 39:215-228.

Reksen, O., Y. T. Grohn, O. Havrevoll, T. Bolstad, A. Waldmann, and E. Ropstad. 2002. Relationships among milk progesterone, concentrate allocation, energy balance, milk yield and conception rate in Norwegian cattle. Anim. Reprod. Sci. 73:169-184.

Roche, J. R., J. M. Lee, K. A. Macdonald, and D. P. Berry. 2007. Relationships among body condition score, body weight, and milk production variables in pasture-based dairy cows. J. Dairy Sci. 90:3802-3815.

Schindler, H., S. Eger, M. Davidson, D. Ochowski, E. C. Schermerhorn, and R. H. Foote. 1991. Factors affecting response of groups of dairy cows managed for different calving conception intervals. Theriogenology 36:495-503.

van Amburgh, M. E., D. M. Galton, D. E. Bauman, and R. W. Everett. 1997. Management and economics of extended calving intervals with use of bovine somatotropin. Livest. Prod. Sci. 50:15-28.

Walsh, S. W., E. J. Williams, and A. C. O. Evans. 2011. A review of the causes of poor fertility in high milk producing dairy cows. Anim. Reprod. Sci. 123:127-138. 